Rakenteiden Mekaniikka (Journal of Structural Mechanics)

Vol. 50, No 3, 2017, pp. $330-332$

https://rakenteidenmekaniikka.journal.fi/index

https://doi.org/10.23998/rm.64923

(c) The author(s) 2017.

Open access under CC BY-SA 4.0 license.

\title{
Cylinder head design of experiment by using the Wärtsilä Digital Design Platform
}

\author{
Massimo Cattarinussi ${ }^{1}$, Anton Leppänen, Juho Könnö and Tero Frondelius
}

Summary. Cylinder Head Design of Experiment (DOE) was carried out by using the Wärtsilä digital design platform. The overall goal has been to create a simulation process to perform a complete cylinder head thermal-structural calculation and create a DOE over that process to vary the inputs, the geometrical parameters under optimization, in a fully automatic workflow. The outputs, uploaded to the DOE activity, were used to rank the input effects on the output response, to capture response sensitivity to input changes, to identify parameter interactions and, at the end, to estimate the optimal design.

Key words: 3D Experience, Wärtsilä Digital Design Platform, Design of Experiment, fatigue, cylinder head, FEM, CFD, Wärtsilä

Received 15 June 2017. Accepted 18 August 201\%. Published online 21 August 2017.

\section{Introduction}

A DOE activity for optimizing geometrical parameters for a new cylinder head is implemented by using the Wärtsilä digital design platform $[5,1]$. The overall goal is to create a simulation process to perform a complete cylinder head thermal-structural calculation and create a DOE over that process to vary the inputs, the geometrical parameters under optimization, in a fully automatic workflow. In the digital design platform, the simulation process is created by a sequence of activities, represented by blue blocks, organized in a workflow according to the specific calculation process $[6,7]$. Each activity contains a sequence of adapters that represent how the task is achieved (Figure 1).

\section{Simulation process}

The simulation process is performed for the assembly which includes all the main components connected to the cylinder head [7]. The specific simulation process workflow consists of a main DOE activity that reads input and output parameters from the activities contained in its subflow. DOE provides as the input to the first activity of its subflow, the NX one, a set of values of the parameters under optimization. For each input parameter,

\footnotetext{
${ }^{1}$ Corresponding author. massimo.cattarinussi@wartsila.com
} 


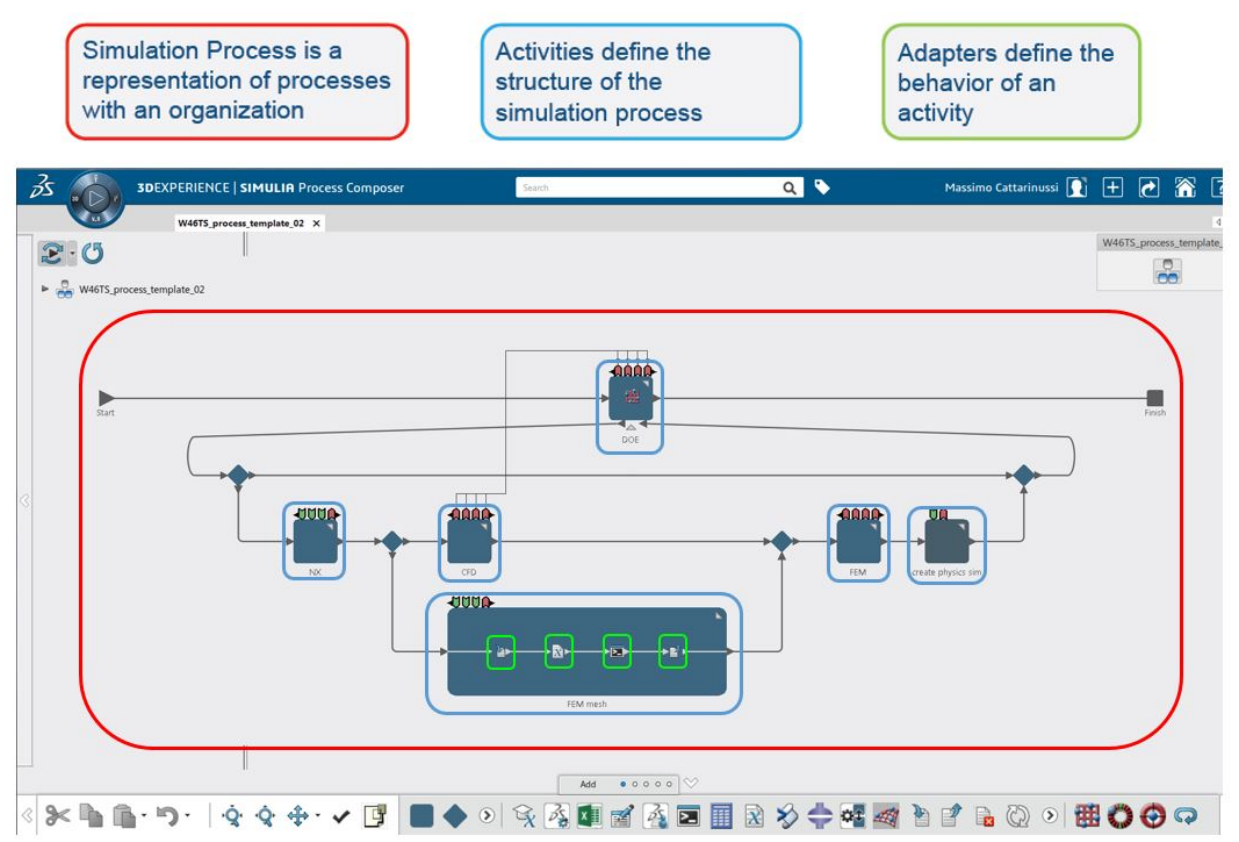

Figure 1. Cylinder head DOE simulation process

there are defined a range of variability and a number of splitting points of the ranges on the basis of the DOE technique chosen [8].

In the NX activity the new 3D CAD is changed according to the input parameter values coming from the DOE activity. The output is a Parasolid file for the next two different activities executed in parallel, the CFD and the FEM mesh activities.

In the CFD activity the component temperatures are simulated with the Star-CCM+ software [4] as conjugate heat transfer simulation where both the thermal load from combustion and the cooling water flow are simulated at the same time [7].

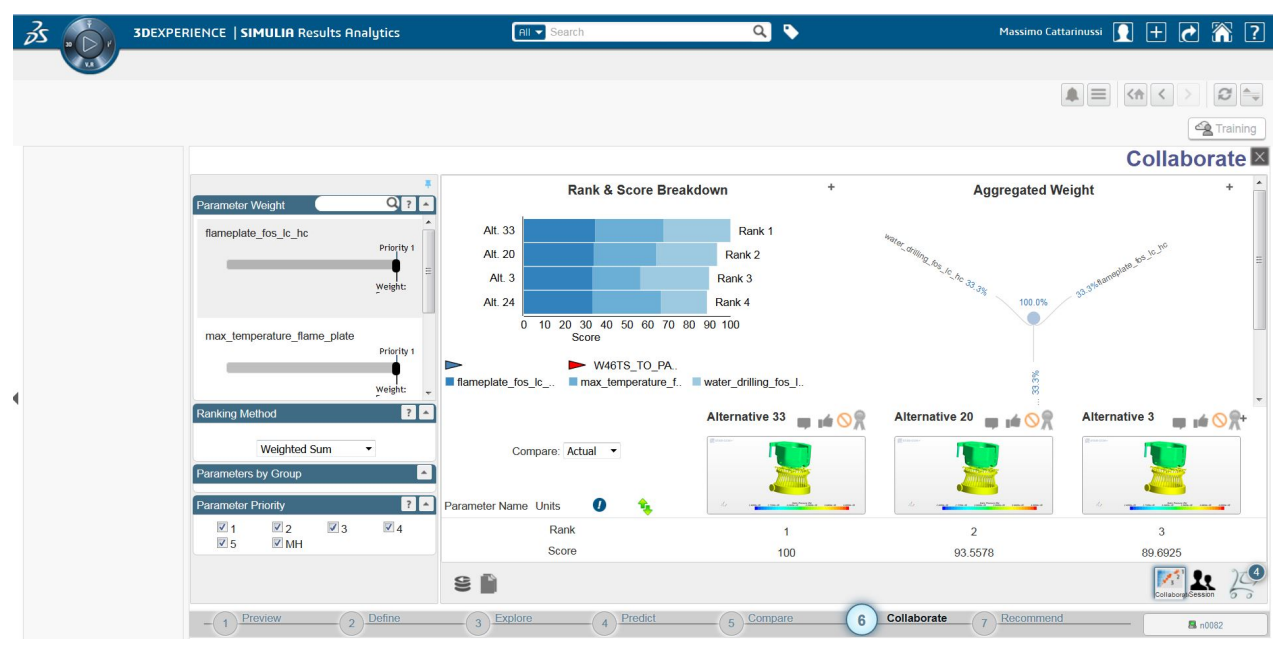

Figure 2. DOE estimate optimal design

In the FEM mesh activity, all the components are meshed and the assembly contacts defined, considering shrink fits and clearances according to the instructions of the internal adapters. 
The next activity, the FEM one, is related to the calculation of the stresses and strains caused by assembly and the thermal and cylinder pressure loads with ABAQUS finite element simulation [3] and the lifetime estimation with fe-safe SIMULIA software [2]. The fe-safe SIMULIA software provides the lifetime estimation for each point in the cylinder head, taking into account the engine operating profile and a critical plane multi-axial fatigue algorithm [2].

More than a hundred output parameters, to upload into DOE activity, are defined. The most important ones are the lifetime estimation for the cylinder head according to a specific engine operating profile, temperatures, deformations and contact pressures for the main assembly components. Finally, all outputs are uploaded to the DOE activity for a post-processing analysis.

With the DOE post-processing, it is possible to rank the input effects on the output response, to capture the response sensitivity to input changes, to identify parameter interactions and, finally, to estimate the optimal design (Figure 2).

\section{References}

[1] Dassault Systemes Simulia Corp. 3dexperience - process composer essentials, 2016.

[2] Dassault Systemes Simulia Corp. fe-safe user guide, 2017.

[3] Dassault Systemes Simulia Corp. Abaqus theory guide. 2017.

[4] STAR-CCM+ User Guide. version 10.02, 2015.

[5] Juho Könnö, Hannu Tienhaara, and Tero Frondelius. Wärtsilä digital design platform. Rakenteiden Mekaniikka, 50(3):234-238, 2017. URL https ://doi .org/10.23998/rm. 64621.

[6] Asko Kumpula, Joona Vaara, Anton Leppänen, and Tero Frondelius. Nodular cast iron ONERA fatigue model fitting. Rakenteiden Mekaniikka, 50(3):179-181, 2017. URL https://doi.org/10.23998/rm.64740.

[7] Anton Leppänen, Asko Kumpula, Joona Vaara, Massimo Cattarinussi, Juho Könnö, and Tero Frondelius. Thermomechanical fatigue analysis of cylinder head. Rakenteiden Mekaniikka, 50(3):182-185, 2017. URL https://doi.org/10.23998/rm.64743.

[8] Douglas C Montgomery. Design and analysis of experiments. John Wiley \& Sons, 2017.

Massimo Cattarinussi, Anton Leppänen, Juho Könnö, Tero Frondelius

Wärtsilä

Järvikatu 2-4

65100 Vaasa

massimo.cattarinussi@wartsila.com, anton.leppanen@wartsila.com,

juho.konno@wartsila.com, tero.frondelius@wartsila.com 